\title{
Towards a science of logistics: cornerstones of a framework of understanding of logistics as an academic discipline
}

\author{
Werner Delfmann - Wilhelm Dangelmaier - Willibald Günthner • Peter Klaus • \\ Ludger Overmeyer - Werner Rothengatter · Jürgen Weber · Joachim Zentes • \\ Working group of the Scientific Advisory Board of German Logistics Association (BVL)
}

Published online: 17 August 2010

(C) Springer-Verlag 2010

\section{Preliminary remarks}

The mission of BVL, the nonprofit German Logistics Association, is to act as an integrative platform to promote the awareness for the importance of logistics in industry, science, and the public arena. It aims to represent the entire spectrum of logistical issues, to develop methods and processes to contribute to the solution of these issues, and to promote and continuously optimise the application of relevant solutions.

The authors are members of a working group of the Scientific Advisory Board of German Logistics Association (BVL).

\author{
W. Delfmann $(\bowtie)$ \\ University of Cologne, Cologne, Germany \\ e-mail: delfmann@wiso.uni-koeln.de \\ W. Dangelmaier \\ University of Paderborn, Paderborn, Germany \\ W. Günthner \\ Technical University Munich, Munich, Germany \\ P. Klaus \\ University of Erlangen-Nürnberg, Nuremberg, Germany \\ L. Overmeyer \\ University of Hannover, Hannover, Germany \\ W. Rothengatter \\ Technical University Karlsruhe, Karlsruhe, Germany \\ J. Weber \\ Otto Beisheim School of Management, Vallendar, Germany \\ J. Zentes \\ University of Saarland, Saarbruecken, Germany
}

BVL's Scientific Advisory Board is supporting BVL's mission by promoting the dialogue between logistics practice and the academic community. Its members come from many different academic backgrounds. While there is no longer any disagreement about the enormous practical relevance of logistics and its steadily growing impact upon day-to-day economic activities, the members of BVL's Scientific Advisory Board are aware that there still is no widely shared understanding of the identity of logistics as a scientific and academic discipline.

Against this backdrop, and following a strategic discussion which the Scientific Advisory Board initiated some time ago, the idea of developing a framework of understanding for logistics as an academic discipline emerged. For this purpose, a working group was set up comprising the authors of this paper. It reflects the broad spectrum of disciplinary backgrounds and perspectives on the essence of science represented on the Advisory Board. Five key points, as outlined below, were agreed upon as the cornerstones of an understanding of logistics as an academic discipline. They were arrived at as the result of an extremely exciting sequence of discussions which took place in the group's workshop sessions. The cornerstones are designed to serve as a point of reference for continuing indepth, discussions about the "science of logistics" within BVL, and-hopefully-with academics and logistics practitioners all over the world. A further aim is to contribute to a better understanding of the depth and relevance of the science of logistics among those "outside" the discipline.

The paper starts out with a statement summarising the nature of logistics as a science. This statement is followed by five cornerstone points elaborating the essential characteristics of the discipline. 


\section{The science of logistics: basic understanding}

Logistics is an application-oriented scientific discipline. It models and analyses economic systems as networks and flows of objects through time and space (specifically goods, information, moneys, and people) which create value for people. It aims to supply recommendations for action on the design and implementation of such networks through accepted scientific methods. The scientific questions of the discipline relate primarily to the configuration, and organisation of these networks and to the mobilisation and control of flows. Its ultimate goal is progress in the balanced achievement of economic, ecological and social objectives.

\section{Five cornerstones to an understanding of logistics as a science and its identity as an academic discipline}

1 The object of enquiry: flows in networks

The approach of scientific logistics is different from other disciplines due to its interpretation of economic systems as networks and of economic processes as flows of objects such as goods, information, people, and money. Logistics identifies, describes, analyses and improves these networks and flows of objects through the application of multiple disciplinary perspectives and research methods. The ultimate aim of logistical scientific inquiry is the balanced achievement of economic, ecological, and social goals.

The goal of economic activity is to secure and improve the material existence of people and society in a lasting way in a context characterised by finite and scarce resources ("economic goals")—-while also taking account of environmental conditions ("ecological goals") and the basic principles of social coexistence ("social goals"). The science of logistics contributes to the achievement of those goals by interpreting economic activities and processes as flows of goods, information, people and moneys. This is the fundamental characteristic of the approach to scientific inquiry and constitutive element of the field's scientific identity. Moreover, a multiperspectival model is adopted, which means that logistics processes are illuminated from different perspectives with different methodological approaches, in particular from a technical, an organisational, and a social point of view.

The technical perspective refers to the interplay of infrastructures (e.g. roads, railways, and warehouses), machines (e.g. trucks, forklifts, and industrial vehicles), receptacles (e.g. containers and pallets) and people (e.g. picker, forklift operator, and truck driver) in flow systems. Technical issues arise on all levels of logistics. Complex material flow systems are made up of widely differing components, and the interplay of these components needs to meet the specific requirements in question. In order to ensure that material flows are controlled in a logistics-compatible way, there are numerous widely varying technical organisation and design principles for the implementation of conveying and storage concepts for goods with different properties.

The organisational perspective focuses first on the administrative level of the transactions that activate these flows. The emphasis is on processes like ordering or replenishment, order processing, internal cost allocation and service remuneration. A second level of this perspective relates to the structure of the networks- the number, type and activities or service programmes of the involved institutions or actors. A further level relates to the dimensionalities of the flows (e.g. volumes, times, speeds of the flows of goods) as well as the dimensionalities of the hubs in the networks (logistics infrastructure).

Despite the technical nature of many of these processes, people - and hence a social perspective-play a decisive role in logistics. The necessity to specifically model people as actors always arises when the people in question possess levels of freedom which they can utilize in their actions. In view of their special importance for logistics problem solutions, we make reference (by way of example) to three assumptions about human beings as elements in the modelled human-and-machine systems who can be differentiated as ideal types based on the people involved.

- "Technical" consideration of the human being. People are production factors and/or market actors. Their behaviour can be anticipated in the same way as that of technical elements in the flow system under consideration. In the field of business management, the corresponding issues are found in the field of production theory and operations research. There are very special challenges in the modelling process due to the high complexity and the dynamic nature of the problems in the area of logistics.

- Consideration of human beings as actors with limited rationality. This kind of modelling is appropriate if actors possess a discretionary freedom of action in flow systems which influences the solution to the problem in question. Transaction cost theory, for example, supplies suitable insights, above all when it comes to coordination issues. A further example is relationship between suppliers and customers, an area in which the principal agent theory provides suitable information on the organisation of such relationships.

- Further enrichment of the basic model of the homo oeconomicus. A third type of model refers back to approaches in the field of behavioural science which 
result in changes to further basic characteristics of the model of the homo oeconomicus. These are replaced by assumptions that are seen as being more realistic (such as the replacement of the maximisation rule by a satisfaction assumption or the modelling of different forms of cognitive limitations). With regard to the coordination aspect of logistics, this opens up a broad spectrum of application for a perspective of human actors that has been extended in this way. For example, the area of interface research shaped by insights into behavioural science can supply various pointers as to how cooperation and collaboration between different departments involved in the flow of materials and goods should be organised in order to meet logistical goals. The construct of mental models is a further example. This provides a means of operationalising the integration of flow orientation as a fundamental way of thinking in modern companies.

Each organisational optimisation step needs to take account of the resulting social and ecological effects. They may have impact not only upon the people actively involved in the processes, the organisation and execution of logistics processes but also upon people who are not immediately involved in these processes. Reactance attitudes of the employees concerned or resistance from ecological stakeholders can counteract the successful implementation of new systems. This is why it is increasingly also the case in the logistics field that the social perspective is being combined with an ecological perspective to form an eco-social perspective. With regard to the flows in networks, this concerns resource economy or efficiency on the one hand and consideration of ethical aspects, in terms of such things as working conditions, remuneration systems, etc. on the other. Ecological objectives or ecological marginal conditions can induce innovative technical solutions and may additionally make good economic sense due to a higher level of resource efficiency. By taking these kinds of interactions into account, the network perspective of logistics is geared towards the balanced consideration of the various goal dimensions of sustainable economic activity.

As the use of the logistical perspective means that the entire flow of economic processes is the subject of investigation, these processes should be ideally considered across organisational, legal or political borders (departmental, company, national boundaries etc.). This supplies a more complete picture of the kind that is to be aimed for when searching for an optimum solution. Cross-interface consideration of economic systems as flows of goods and information also makes it far easier to see the connections between the individual flows that result in logistics networks. The consideration of networks as an extension of the flow concept also paves the way for a further abstraction of the real processes and for the abstract description of these processes.

2 Logistical inquiries on consecutive levels of aggregation: self-similarity of the network model

Scientific logistical inquiry may refer to different sections and different levels of aggregation of economic systems. The approach of scientific logistics is open to a wide range of issues. The network model is generic because of its property of self-similarity. Any logistical issue can be interpreted as a networks of flows, which may be part of a higher-level network.

Economic activity takes place on the level of individual actors or extremely small business entities ("micro level"), in constellations of interacting business entities in supply and value chain relationships ("supply chains", "meso level") and also through the (where applicable, worldwide) interaction of entire sectors, regions and national economies ("macro level"). Logistics addresses the facts and issues of economic activity on all these levels and helps to systematically configure, organise, control and regulate these activities in such a way that economic, ecological and social goals can be achieved more effectively.

Investigations regarding individual actors and actions in the field of production, trade and consumption are in focus at the level of micrologistics. It is on this level of consideration that intralogistics is primarily located. Intralogistics is about the organisation, control or regulation, handling and optimisation of the in-house material flow, the flows of information and the transshipment of goods in industry, commerce and public institutions. Production, procurement, distribution, and the exchange of intermediate input take place at different times and places, however, with the result that logistics service providers (e.g. freight forwarders as well as transport, warehousing and transshipment companies) come onto the scene as additional actors between dispatchers and recipients in the value added chain. The role of micrologistics is the cost-effective organisation of the activities and interactions in these kinds of elementary relationship networks.

This concerns, for example:

- in the case of the producer: part production, final assembly, batch sizes, procurement, distribution and warehousing

- in the case of the trader: orders, deliveries, replenishments

- in the case of the freight forwarder: grouping, consolidation, sequencing, buffering, storage, value added services

- in the case of the transport company: itineraries, routes, choice of vehicle, deployment of drivers, etc. 
In principle, the individual logistical problems can be addressed using instruments from existing scientific disciplines like mathematics, business management, transport science or engineering science. However, the solution of overall problems calls for the additional consideration of the links between the sub-areas and the interactions between the actors involved in the processes. As a sub-area of logistics, supply chain management focuses on this interaction issue. The application context of logistics supplies complex and dynamic problem structures that require independent scientific solutions. The contributions made by logistics to processes like production and distribution, location and transport planning or parts production and procurement clearly show that its role is by no means passive or derived from upstream or downstream economic activities. On the contrary: logistics makes truly original contributions- to the planning processes that induce transport, for example, processes that will become increasingly important in future in direct proportion to the degree to which requirements related to energy economy and climate protection are reflected in the cost calculations of the relevant actors.

On the level of mesologistics, constellations and aggregations of several actors are observed that supply typical structural patterns with connections to logistics. These groupings include, for example, (horizontal or vertical) cooperation ventures, alliances and associations. The classifications are sectors or transport segments, and the arrangements are markets or sub-markets that regulate logistic needs. The mesologistics level is reflected, for example, in the transport function:

- in cooperation processes, alliances and associations (efficient network design)

- in classifications based on sectors or classes of goods (transport affinities or transport elasticities)

- in classifications based on transport segments (intermodal transports),

- in (sub-) markets based on type of consignment (bulk goods, general cargo, containers, hazardous goods)

On this level, it is possible to make use of scientific instruments from the fields of network analysis, game theory, industrial economics, market theory, and transport network modelling. Normative models for benefit maximisation or cost minimisation compete with positive or explicative models that explain the behaviour of the actor groups on the basis of routines and uncertainty avoidance. On the transport routes, the combination of drivers, vehicles, and infrastructure characteristics results in complex interaction patterns that impact the times and costs of the transport process. The stochastic component of the interaction findings calls for independent research approachesfor which purpose the standard models of the quantitative disciplines need to be supplemented.
The macro level refers to the aggregate perspective on the level of a country, a community of states (e.g. the EU) or the whole world. Macrologistical issues concern, for example (based in this case on the transport sector):

- transport infrastructures, ports, airports, corridors, (global) transshipment hubs

- regional, national and international transport flows

- transport modes, transport routes, transport organisation

- cross-border trade flows, import and export

- aggregated transport flows like internal, source, target, transit transport

- aggregated transport indicators like volume, transport capacity, mileage capacity

In the analysis and prediction of the overall flow of goods, the macro level plays a role insofar as the overall demand for transport services in a particular country is highly dependent on international trade and national production. The slump in freight transport and logistics as a result of the global economic crisis is directly due to the decline in foreign trade movements. A further topic area is the macroeconomic significance of logistics.

The subdivision into different levels of consideration serves the purpose of analytical clarity and demarcation of special areas of research. In reality, the various levels are fully interlinked with one another. Each logistical element can itself be viewed both as a network and as part as of a superordinate network. In holistic system analyses, the focus is on these very relationship components and on the feedback between decisions on the micro level and the system reactions on meso and macro level.

3 Interdisciplinarity of logistics

Logistical inquiry is unique in its aspiration to overcome the boundaries of established application-oriented scientific disciplines such as business administration, economics, engineering, informatics, the social sciences, etc., all of which also contribute to the achievement of economic, ecological, and social objectives. Logistics is rooted in these disciplines, but aims to advance knowledge through the synergistic combination of the knowledge bases of these root disciplines.

As an application-oriented science, logistics uses methods from other disciplines (e.g. mathematics, engineering, economic science, social sciences) but also develops them further. Although every scientific discipline builds on other sciences and is therefore interdisciplinary, this is particularly true of logistics due to its specific focus and its multiperspectival approach. The declared aim of logistics, as has been shown, is to model economic systems as networks, to analyse their links and connections and thereby to obtain information for the optimum organisation and implementation of these networks. 
At this point, it becomes particularly clear why the specific interest of logistics necessitates a perspective that extends beyond established scientific disciplines and that, in this respect, transcends these disciplines. As a scientific discipline, logistics not only builds on the traditional sciences, as do other application-oriented disciplines, but also connects application-oriented sciences like micro and macroeconomics, engineering, (business) information science, economic geography or law in order to generate new, specifically logistical insights. To this extent, logistics as a scientific discipline is more than a sub-area of just one of these sciences; rather, it aims to connect the knowledge bases of different disciplines and thus to overcome established discipline-specific boundaries. Seen from this point of view, interdisciplinarity is of central importance for logistics and is of a significance exceeding that for any application-oriented science. It is a central element of the logistics paradigm.

It goes without saying that this interdisciplinarity does not rule out the possibility that individual logistical analyses or fields of research are focused on specific issues within the various established scientific fields and can therefore only be described as "interdisciplinary" to a limited degree. This is quite simply due to reasons of scientific economy. The direct and logical consequence of this is that there are specialised logistics-oriented fields in the established application-oriented scientific disciplines-business management logistics, for example, or engineering logistics.

4 Unity within a variety of terminological, conceptual, and methodological foundations of logistics through the network model

Logistics as a science unites the terminological, conceptual and methodological variety of its various root disciplines through its approach of observing and analysing economic systems as networks of flows and objects.

The particular nature of logistics as a scientific discipline-namely, its interpretation of economic processes as flows of goods, information, people, moneys and other objects and its multiperspectival approach to research on these networks - brings with it the challenge of not only making use of the methods of other disciplines (such as mathematics, engineering, economics, the social sciences), but of creating a terminological, methodical and conceptual and terminological framework. It should integrate and condense these different perspectives to form the independent core of a system of inquiry that is clearly defined across the various perspectives, that is non-contradictory and that additionally allows "permeability" between the perspectives from which logistics receives a significant input. The terminological approach (of a theory) of logistics formally defines the object of logistical enquiry and experience.
The primary object of enquiry of logistics, i.e. "flows of goods, information, people, assets and other objects" and the relationships and connections that can be derived within the context of economic systems determines the focus and boundaries of the field with respect to suitable research methods and theoretical content.

Specifically, logistics draws from mathematics, information science, operations research, the social sciences etc. Formal description, or special models from other disciplines like physics or biology are applied to logistics using analogy relationships. The discipline of business management, whose originally in-house-motivated concepts are transferred to inter-organisational relationships. But beyond the adaptation of methods and content from other disciplines logistics is to be seen in an active role: a theory that is satisfactory based on the scientific state of the art and real-world empirical application must always look for better, more efficient etc. concepts and more logical explanations. This means that we need to improve the way in which we describe logistics problems (terminology), the way in which we incorporate these problems in models and the way in which we solve these problems.

5 Application orientation of logistics science

As an application-oriented science, logistics seeks to primarily address problems and research questions that are faced in real-world economic activities such as the optimization of time regimes, meeting the challenges of sustainable economic activity, and of the transfer of logistical know how from the world of material industrial production to other fields of application. It aims to contribute proactively to an ever deeper understanding of such problems and to provide relevant solutions.

\section{- Optimal time regimes in flow systems}

Logistics explicitly deals with time-based characteristics and the search for optimum time regimes for the flows and processes in question. This may mean a systematic quest for acceleration, pacing and agitation or, in other cases, for deceleration and process slowing. The choice depends on the framework conditions and on the stipulated economic, ecological, and social objectives. The understanding of practical logistics as a generally reactive instrument for the fulfilment of defined market requirements is still widespread. In contrast to this narrow interpretation, it is of fundamental importance to understand and/or continue to develop logistics as a proactive organisational activity. On a situation-specific basis, logistical analyses have to indicate how economic systems are to be organised in the context of changing framework conditions so that the defined economic, ecological, and social objectives can be achieved. 
Parallel to outlining the logistical requirements and consequences of market-based goals (on micro, meso and macrologistical level), it is therefore also the job of logistics to ensure transparency with regard to the objective of increased sustainability. It is precisely for this task that an interdisciplinary and multiperspectival logistics approach is an essential precondition. The necessity and the individual and overall economic benefits of this kind of application-oriented and proactive logistics is shown, for example, in the following areas:

\section{- Logistical sustainability of value added systems}

Due to the structural complexity of logistics systems, it is increasingly the case that the efficient use of resources and rapid adaptation to changing environmental conditions are reaching their limits. In addition, the share of transport costs in the overall process of service provision is set to increase, at least in the medium term, and this poses new challenges for logistics systems. In particular, the use of energy-intensive modes of transport sharpens the focus on the consolidation of goods and the accompanying creation of inventories as well as the targeted extension of delivery times. Established assumptions on customer needs and buyer behaviour need to be critically reviewed. If ever more complex logistics systems fail to generate additional benefits for the customer, then we need to rethink current business models.

The holistic consideration of logistics systems also calls for the inclusion of external factors like capacity utilisation of the transport infrastructure and the use of natural resources. Due to scarce resources and fully utilised transport routes, transport operations are fast reaching their limitslimits that can only be overcome in the long term by the use of renewable sources of energy and raw materials. In the short and medium term, a changeover to energy-efficient modes of transport seems a logical step; what is above all necessary, however, is the adaptation of logistics network structures and business processes. Although infrastructure expansion can go some way towards solving the problem of fully utilised transport routes, the limits to such a process of expansion would necessitate the development of new solution models in this area as well. In view of these far-reaching changes to the framework conditions, proactive logistics concepts will tend to be geared more to deceleration and to focus on simple and decentral logistics structures and processes that can show that they are economically, ecologically and, last but not least, socially advantageous and that they are therefore sustainable.

- Active transfer of logistical know-how to other fields

As a scientific discipline, logistics has to date primarily become established in economic systems for the domain of physical objects (transfer of goods and persons). On the one hand, proactive logistics also means analysing the transferability of proven logistics concepts to other domains that may be of advantage for the logistical paradigm of object flow modelling in networks. This could, for example, apply to service processes or flows of finance, possibly also information and communication systems. On the other hand, the transfer of logistical know-how to systems that are not primarily of an economic nature holds major potential for progress. This could apply to medical, social or humanitarian areas of application like disaster protection or precarious supply situations. In this context, the question of the interfaces between micro, meso, and macrologistics is a particular focal point of interest.

- Further development of the logistics of virtual systems

With the modelling of (object) flows in networks, logistics has to date focused on structured economic systems. These systems are characterised by a long-term structure on which the logistical "advantage assumptions" are based. The structured nature of economic systems decreases in proportion to the speed of continuous change; in other words, the elements and relations of the system are subject to constant change. The goal for the future must be to actively develop logistics to master these kinds of systems, which are sometimes described as "virtual".

- "Return transfer" of logistical insights into other areas of science

As outlined earlier, logistics specifically builds on insights and concepts from other scientific disciplines. To this extent, it is an interdisciplinary science. The specific paradigm of logistics is to combine these fundamental insights using a multiperspectival approach and to use the outcomes of this process for the modelling of (object) flows in networks. It is exactly this that results in the increase in specifically logistical insights - the insights that represent the core of logistics as a scientific discipline. These advances in knowledge now also hold potential for progress through return transfer to the scientific disciplines from which logistics receives its input. For example, logistics should also be able to supply information for the further development of its basic application-oriented disciplines like business management or macroeconomics-as well as, under certain circumstances, also for fundamental disciplines in areas like the methods of operations research, technical basics in the engineering sciences or behavioural science approaches in the field of psychology or sociology.

The key points outlined earlier stake the claim of logistics as an independent scientific discipline. They also indicate the points of contact and overlaps with as well as the differences to established scientific disciplines. For probably the first time, therefore, a reference paper exists which serves as a platform for the future discussion of the 
self-conception of logistics, a discussion in which the authors cordially invite readers to partake.

Source: Delfmann et.al.: Eckpunktepapier zum Grundverständnis der Logistik als wissenschaftliche Disziplin in: Strukturwandel in der Logistik-Wissenschaft und
Praxis im Dialog, Werner Delfmann, Thomas Wimmer (ed.), DVV Media Group I Deutscher Verkehrs-Verlag, Hamburg, 2010, p. 3-10. Translation by Anthony TranterKrstev, edited for the purposes of publication in LOGISTICS RESEARCH by Peter Klaus. 